\title{
Epidemiological scenario of Dengue in the state of Manipur during the last 3 years
}

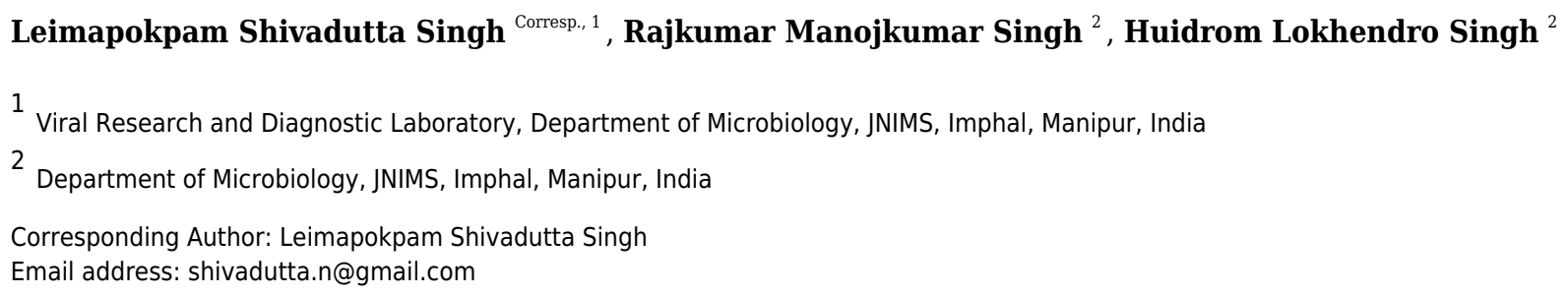

Background. The study of disease transmission of dengue fever (DF) is perplexing in the Indian subcontinent as all the four serotypes are circling. Also, there is no efficient epidemiological examination done on dengue cases in Manipur, a north-eastern territory of India. Method. We utilized the dengue information extricated from the lab register of Viral Research and Diagnostic Laboratory (VRDL) from 2016 to 2018. All presumed outpatient and inpatients dengue cases from open and private health-care facilities are incorporated into the VRDL database whose informed consent were gotten. Results. A sum of 1689 instances of associated patients with dengue infection was tried for dengue ELISA test and $272(16.10 \%)$ samples were seen as seropositive. The month-wise conveyance of dengue cases is very intriguing as the three years of study demonstrates a variation design in perception. In all the three years dengue seropositive cases were seen higher in the male populace. Be that as it may, there is no noteworthy incentive to the inspiration of dengue seropositive towards male than female. Conclusion. Our examination exhibits a comparative epidemiological investigation on seroprevelance of dengue in the province of Manipur for three years. This is an endeavour to show epidemiological dengue seroprevelance in the territory of Manipur which in future would be a reference from general wellbeing worries for making up essential move intend to shorten the spread of dengue. 
1 Epidemiological Scenario of Dengue in the State of Manipur During the last 3 years

2 Leimapokpam Shivadutta Singh ${ }^{1}$, Rajkumar Manojkumar Singh ${ }^{2}$, Huidrom Lokhendro Singh $^{3}$

$3 \quad{ }^{1}$ Viral Research and Diagnostic Laboratory, Department of Microbiology, JNIMS, Imphal

4 Manipur, India.

$5 \quad 2$ Department of Microbiology,JNIMS, Imphal, Manipur, India.

$6 \quad{ }^{3}$ Department of Microbiology, JNIMS, Imphal, Manipur, India.

7 Corresponding Author:

8 Leimapokpam Shivadutta Singh ${ }^{1}$

9 Liwa Road Maibam Leikai,Singjamei, Imphal, Manipur, 795008, India

10 Email address: shivadutta.n@gmail.com

11 Abstract

Background. The study of disease transmission of dengue fever (DF) is perplexing in the Indian subcontinent as all the four serotypes are circling. Also, there is no efficient epidemiological examination done on dengue cases in Manipur, a north-eastern territory of India.

Method. We utilized the dengue information extricated from the lab register of Viral Research and Diagnostic Laboratory (VRDL) from 2016 to 2018. All presumed outpatient and inpatients dengue cases from open and private health-care facilities are incorporated into the VRDL database whose informed consent were gotten.

Results. A sum of 1689 instances of associated patients with dengue infection was tried for dengue ELISA test and 272(16.10\%) samples were seen as seropositive. The month-wise conveyance of dengue cases is very intriguing as the three years of study demonstrates a variation design in perception. In all the three years dengue seropositive cases were seen higher in the male populace. Be that as it may, there is no noteworthy incentive to the inspiration of dengue seropositive towards male than female.

Conclusion. Our examination exhibits a comparative epidemiological investigation on seroprevelance of dengue in the province of Manipur for three years. This is an endeavour to show epidemiological dengue seroprevelance in the territory of Manipur which in future would be a reference from general wellbeing worries for making up essential move intend to shorten the spread of dengue. 


\section{Introduction}

Dengue is a mosquito borne flavivirus belonging to the family flaviviridae which is the most extensively spread mosquito-borne disease [21]. It has five distinct serotypes DENV -1, DENV-2, DENV-3 \& DENV-DENV-5 which are distinguished from each other by serological and molecular assays $[16,17]$. These virus are transferred by female Aedes mosquito especially Aedes aegypti and lesser extend Aedes albopictus that feed on human blood both indoors and outdoors during dawn to dusk and can be found in tropical and subtropical region particularly dominant in urban environment and spreading out to rural areas.[18,19,20].

In a Chinese medical encyclopaedia in 992 from the Jin Dynasty (265-420 AD) dengue fever was referred as "water poison" associated with flying insects but the term dengue fever came into general use only after 1828 [23]. Earliest dengue epidemics occurred almost simultaneously in Asia, Africa, and North America in the 1780s and first clinical case report dates from 1789 of 1780 epidemic in Philadelphia is by Benjamin Rush, who coined the term "break bone fever" because of the symptoms of myalgia and arthralgia (quoted from www.globalmedicine.nl/index.php/dengue-fever).

WHO has revealed dengue an arboviral malady as one of the 8 neglected tropical illnesses [1]. It is of worldwide general wellbeing concern causing higher dreariness in a large portion of the endemic areas of the world with around 2.5 billion individuals being influenced [2,3]. Mostly the urban tenants in tropical and subtropical districts have a higher danger of contracting dengue infection as contrast with other regions. [4].According to WHO report dengue cases have expanded 30 fold over the last 50 years and evaluated that 96 million instances of dengue happen every year $[5,6]$.About $75 \%$ of current global disease burden due to dengue is borne by southeast Asian region and Western Pacific regions [7]. Falling in the South East Asian area, India has higher incidence of dengue fever leading to threat in health care system [8]. Since its first confirmed report in 1940s dengue infection in India, more and more new states have been reporting the disease in epidemic proportions often inflicting heavy morbidity and mortality[8].

Early recognition of dengue viral infection disease (DVI) routinely done by the serological test is exceptionally fundamental. IgM antibody is the first immunoglobulin isotype to appear. In a suspected case of dengue, the presence of anti-dengue IgM antibody suggests recent infection. Anti-dengue IgM detection using enzyme-linked immunosorbent assay (ELISA) represents one of the most important advances and has become an invaluable tool for routine dengue diagnosis $[9,22]$.

The study of disease transmission of dengue fever is intricate and remains inadequately comprehended because of the contribution of status of host, viral and vector which are subject to statistic, financial, conduct and changed cultural components. Various perceptions have raised worries against generally acknowledged epidemiological qualities of dengue [10, 11]. 
67 Knowledge of local prevalence of infections is critical in guiding clinical work up and treatment.

68

69

70

71

72

73

As effective control and preventive programs for dengue infection are based upon improved surveillance data, the objective of this study was to report the seroprevalence of dengue virus infection in Manipur to establish an epidemiological viewpoint in reference to current infection.

\section{Material and Methods}

The present study was conducted at Viral Research and Diagnostic Laboratory (VRDL), Department of Microbiology, JNIMS, Porompat, Imphal East, Manipur during a time of three (3) years from January 2016 to December 2018. VRDL was set up by Department of Health Research (DHR), Government of India and Indian Council of Medical Research (ICMR) under process of establishing a network of virology diagnostic laboratories in the country with an aim of strengthening laboratory capacity in the country for timely identification of viral diseases and other agents causing significant morbidity.

The state of Manipur is the easternmost state of India, lying between $23^{\circ} 83^{\prime} \mathrm{N}-25^{\circ} 68^{\prime} \mathrm{N}$ latitude and between $93^{\circ} 03^{\prime} \mathrm{E}-94^{\circ} 78^{\prime} \mathrm{E}$ longitude, bordering Nagaland in the north, Mizoram in the south, Assam in the west and sharing the international border with Myanmar in the east.

All the samples from patient suspected of having dengue fever (as per WHO guidelines) referred to VRDL from the medical facilities (public or private) of the state and also the samples referred directly by state health authorities for suspected dengue cases were all included for the study. The samples consisted blood samples of both inpatient and outpatient collected during acute phase along with a case report form detailing demographic, clinical, and laboratory characteristics. Serum was separated as soon as possible and refrigerated $\left(2-8^{\circ} \mathrm{C}\right)$ or stored frozen $\left(\leq-20^{\circ} \mathrm{C}\right)$, if not tested within $48 \mathrm{hrs}$. Samples obtained within 5 days of onset of fever were qualitatively tested for presence of dengue viral NS1 antigen using the dengue NS1 antigen ELISA (Microlisa J. Mitra \& Co. Pvt. Ltd.) supplied by NVBDCP (National Vector Borne Disease Control Program), Manipur where as samples of patients with fever of more than five days duration at time of collection were tested for the presence of anti-dengue IgM antibodies using MAC ELISA NIV (National Institute of Virology), Pune.

We analyzed the laboratory surveillance data and report proportion of laboratory confirmed dengue by time (month and year), place (district and state) and person (age and sex) characteristics. Data were analysed using MS Excel 2007. Types of analysis included proportions and percentage; tests of significance (Chi-square test). $\mathrm{P}<0.05$ was considered statistically significant.

\section{Results}

A total of 1689 samples of suspected patients of dengue virus infection referred to the VRDL for confirmation of diagnosis of dengue fever over a period of three years, from January 2016 to 
103 December 2018 were considered for this study. Out of these, 272(16.10\%) samples were found 104 to positive for dengue virus positive (seropositive) (Table 1).Based on the number of days of 105 fever, 1394 serum samples were tested for anti-dengue IgM antibodies and 295 for 106 NS1antigen.63 (3.73\%) samples were serologically positive for NS1 antigen and 209 (12.37\%) 107 samples positive for anti-dengue IgM antibodies (Table 1). During this study period, it is seen 108 that dengue was endemically present in the region.

109 In the year 2016 incidence of dengue began by September and peaked during October and 110 sharply decreased by subsequent months. In the year 2017 the incidence of dengue started by 111 May and abruptly rises till the month of August and declining from the month of September 112 onwards. In 2018 the incidence of dengue were seen sparsely distributed throughout the year 113 except in the month of February, May and June with no incidence of dengue (Figure 1, Table 2).

114 Overall for the period of three years most of the dengue cases were seen concentrated in the 115 month of June to October (rainy season) and lesser cases in the month of November till May 116 (Table 2).

117 Seropositive cases in male population were seen little bit higher as compared to that of female 118 during the study period of three years.The proportion of males was found to be higher than 119 females in our study (1.37:1). But such predominance of dengue positivity in male as compared 120 to female is found to be not significant (Table 3).

121 In 2016 almost all the age group were found to be equally infected by dengue except age group 122 of upto 10 years. For the year 2017 highest positive cases were observed in the age groups of 2112330 followed by upto 10 age groups and least was seen in the case of 41-50 age groups. In the 124 year 2018 the highest positive cases were observed in the age group of 11-20 years followed by 125 21-30 age groups while least was seen in the age group of 31-40 and 41-50. (Table 4 \& Figure $1262)$.

127 The dengue positive cases were seen distributed in 6 districts in the year 2016.Imphal West 128 district showing the highest positivity followed by Imphal East. In the year 2017 distribution of 129 dengue positive cases were seen in all the districts of Manipur with Churachandpur district 130 having highest positivity followed by Imphal East, Imphal West. While the least positive cases 131 were observed in Tamenglong district. In the case of 2018 the highest positive cases were from 132 Imphal East district and Thoubal district. While three district namely Bishnupur, Chandel and 133 Tamenglong did not have any positive cases (Figure 3).

134 Overall in the three years maximum dengue positive cases were seen concentrated in 135 Churachandpur district followed by Imphal West, Imphal East, Senapati, Thoubal, Chandel. 136 While Bishnupur, Ukhrul and Tamenglong districts had least dengue positive cases 137 concentration.

\section{Discussion}


139 Spread of awareness of dengue infection among health care workers and public has paved the

140

141

142

143

144

145

146

147

148

149

150

151

152

153

154

155

156

157

158

159

160

161

162

163

164

165

166

167

168

169

170

171

172

173

174

175

176 way of increased serological tests leading to higher rate of detection of dengue cases over the past few years [3]. The endemicity of dengue is spreading and has witnessed a 30-fold increase with rapid expansion to more than 100 countries in Africa, America, Eastern Mediterranean, South-East Asia and Western Pacific areas from urban to rural settings and worst affected regions are South-East Asia and Western pacific regions [26, 27].In this study $16.10 \%$ cases were dengue positive serologically which is lower than the findings of others (Nidhi Singla et al., 2016, Atul et al., 2011 and Shwetha et al., 2018). But the positivity rate of study is found to higher as compared to report of other studies (Sherchand et al.,2001,Shah et al.,2012 and Emran et al.,2002).Such variation in seropositive rate could be due to different geographical areas and climatic conditions [8]

In India, the vulnerability of dengue has increased in recent years due to rapid urbanization, lifestyle changes and deficient water management including improper water storage practices in urban, peri-urban and rural areas, leading to proliferation of mosquito breeding sites [27].

Determining the differences infection rate among male and female is important for public health control programmes. In this study higher incidence of dengue infection among male as compared to that of female was seen. Such higher incidence of dengue infection among male population than female population was similarly reported in other studies (Jimmy et al., 2014; Atul et al., 2011 and Mohan et al., 2013) and could be due to extensive exposure of males to dengue-carrying mosquitoes or differences in the healthcare-seeking behaviour of males and females (Anker and Arima, 2011; Arima et al., 2015).

Dengue infection was found in all the age groups in our study but highest was seen in the age group of 21-30 yrs which is in accordance with the findings of the study done by Sodani S et al., 2015, Rubina et al., 2018 and Deepti et al.,2016. Dengue infection is not age specific and not only children but adults are also equally under threat of dengue infection.

To identify the seasonal variation of the dengue infection, analysis of the data on monthly basis were done. A gradual increase in dengue positivity was noticed from September with a peak in October, in the year 2016 which is quite close to finding by Atul et al., 2011. But in the year 2017 the dengue cases started to increase from the month of May with a peak in July, August. However, the seasonal variation in the year 2018 seems quite different with low level of dengue cases and uneven distribution pattern throughout the year. Such uneven pattern of seasonal variation of dengue infection is quite different from the studies done by Mohan et al., 2013 and Atul et al., 2011. Such pattern is an indication for weak relationship between monthly mean temperature and incidence of dengue as indicated by studies done by Hay et al., 2002. As revealed by the study of Guha et al., 2005 the present study supports the oversimplification of the relationship between temperature, rainfall and increasing vector-borne disease. However the indication of overall dengue infection in the three years of study seen mostly during rainy season

Peer] reviewing PDF | (2019:05:37443:1:2:REVIEW 23 Nov 2019) 
177

178

179

180

181

182

183

184

185

186

187

188

189

190

191

192

193

194

195

196

197

198

199

200

201

202

203

204

205

206

207

208

209

210

211

of the state (June-October) indicates its correlation with monsoon season. Moreover anthropogenic climate change due to human activities such as extensive urbanization, explosive growth of population, deforestation/degradation of forests for industrialization, increasing emissions of fossil fuel, waste disposal etc. may have paved a way for increase of vector borne diseases such as dengue (Ganesh Sethi et al., 2017).

\section{Conclusion}

The present study reveals that the prevalence of dengue cases in the State of Manipur with differential pattern of distribution with respect to geographical, age wise and season wise. The findings in the present study extend the knowledge of the geographical distribution and seroprevelance of dengue in the state of Manipur for the last three years. This study is the first to provide a consistently derived overview of dengue seropositivity data for the state. Given that the majority of dengue infections are clinically asymptomatic, and that the disease is greatly underreported, these results provide distinctive information on dengue transmission per age group in the different districts of the state, and will be invaluable in future modeling studies that explore the temporal and spatial distribution of dengue infection.

This is an attempt to present epidemiological dengue seroprevelance in the state of Manipur which in future would be a reference from public health concerns for taking up necessary action plan to curtail the spread of dengue. Surveillance of dengue cases is still warranted to be vigilant about any new genotype introduction in the endemic districts.

\section{Acknowledgements}

We acknowledge our laboratory technician Mr Kh Bipin Singh and Mrs Sulla Yumnam for their technical support.

References

1. World Health Organization. Neglected tropical diseases. WHO press; 2016; Available from www.who.int/neglected-diseases/disease/en/2016.

2. World Health Organization and the Special Programme for Research and Training in Tropical Diseases (TDR). Dengue: Guidelines for Diagnosis, Treatment, Prevention and Control. Geneva, Switzerland: WHO Press; 2009. p. 3-147. Available from: http://www.whqlibdoc.who.int-publications-2009-9789241547871_eng.pdf.

3. Sodani S, Ahirwar S, Mutha A, Hawaldar R. Retrospective study and evaluation of rapid and ELISA tests for diagnosis of dengue in a tertiary care hospital. Panacea Journal of Medical Sciences, May - August 2015:5(2); 81-84.

4. Halstead SB. Dengue. Lancet. 2007 Nov 10;370 (9599):1644-52.

5. WHO, Dengue Guidelines for Diagnosis, Treatment, Prevention and Control: New Edition, (2009), pp. 1-147 http://www.who.int/rpc/guidelines/9789241547871. 
212

213

214

215

216

217

218

219

220

221

222

223

224

225

226

227

228

229

230

231

232

233

234

235

236

237

238

239

240

241

242

243

244

245

246

247

248

249

250

251

252

6. S. Bhatt, P.W. Gething, O.J. Brady, J.P. Messina, A.W. Farlow, C.L. Moyes,J.M. Drake, J.S. Brownstein, A.G. Hoen, O. Sankoh, M.F. Myers, D.B. George,T. Jaenisch, G.R. Wint, C.P. Simmons, T.W. Scott, J.J. Farrar, S.I. Hay. The global distribution and burden of dengue, Nature 496 (7446) (2013) 504-507.

7. Garg A, Garg J, Rao YK, Upadhyay GC, Sakhuja S. Prevalence of dengue among clinically suspected febrile episodes at a teaching hospital in North India. J Infect Dis Immun. 2011; 3:85-89.

8. Dr. Mohan D Kashinkunti, Dr. Shiddappa, Dr. Dhananjaya M. A Study of Clinical Profile of Dengue Fever in a Tertiary Care Teaching Hospital. Sch. J. App. Med. Sci., 2013; 1(4):280-282.

9. Kuno G, Cropp CB, Wong-Lee J, Gubler DJ .Evaluation of an IgM immunoblot kit for dengue diagnosis. Am J Trop Med Hyg 1998 59:757-762.

10. Guha-Sapir D, Schimmer B. Dengue fever: New paradigms for a changing epidemiology. Emerg Themes Epidemiol 2005; 2:1.

11. Guzman $\mathrm{MG}^{1}$, Halstead SB, Artsob H, Buchy P, Farrar J, Gubler DJ, Hunsperger E, Kroeger A, Margolis HS, Martínez E, Nathan MB, Pelegrino JL, Simmons C, Yoksan S, Peeling RW. Dengue: A continuing global threat. Nat Rev Microbiol 2010; 8 (12 Suppl):S7-16.

12. Rubina Paul, Loveena Oberoi, Kanwardeep Singh, Pushpa Devi. Molecular Characterization and Serological Analysis of Dengue Viruses in Amritsar District. International Journal of Contemporary Medical Research 2018;5(3):C10-C14.

13. Xiaoxi O, 2, Xin J, Dayong G, Yaou Z, S.K. Kong, Chaoxin, Weidong X. Dysregulated Serum MiRNA Profile and Promising Biomarkers in Dengue-infected Patients. Int. J. Med. Sci. 2016; 13(3): 195-205.

14. Gupta D, Jain SB, Jain B, Ranjan KP.Comparative analysis of clinicopathological findings with immuno-logical and molecular tests for early diagnosis and confirmation of dengue in a tertiary-care hospital in Gwalior. Int J Med Sci Public Health 2016;5:171-175.

15. Jimmy Antony,T.M.Celine.A descriptive study on dengue fever reported in a Medical College Hospital.Sahel Medical Journal.2014;17(3):83-86.

16. Rice CM, Strauss EG, Strauss JH.Structure of the flavivirus genome,In S.Schlesinger a $\mathrm{d}$ M. J.Schlesinger th e Togaviridae and Flaviviridae. Plenum, New York, 1986 p.279-326.

17. Borkakoty B, Das M, Sarma K, Jakharia A, Das PK, Bhattacharya C, Apum B, Biswas D. Molecular characterisation and phylogenetic analysis of dengue outbreak in Pasighat, Arunachal Pradesh, Northeast India.Indian J Med Microbiol 2018;36:3742.

18. Mustafa MS, Rasotgi V, Jain S, Gupta V. Discovery of fifth serotype of dengue virus (DENV)-A new public health dilemma in dengue control. Med J Armed Forces India. 2015; 71(1):67-70.

19. Brady OJ, Golding N, Pigott DM, Kraemer MU, Messina JP, Reiner RC Jr, Scott TW, Smith DL, Gething PW, Hay SI.Global temperature constraints on Aedes aegypti and Ae. 
albopictus persistence and com-petence for dengue virus transmission. Parasit Vectors. 2014; 7:338.

20. Saboor Ahmad, Muhammad Asif Aziz, Asad Aftab, Zia Ullah, Muhammad Irfan Ahmad and Abdul Mustan. Epidemiology of dengue in Pakistan, present prevalence and guidelines for future control. International Journal of Mosquito Research 2017; 4(6): 25-32.

21. Manoj Murhekar, Vasna Joshua, K. Kanagasabai, Vishal Shete, M. Ravi,R. Ramachandran, R. Sabarinathan, B. Kirubakaran,Nivedita Gupta,Sanjay Mehendale. Epidemiology of dengue fever in India, based on laboratory surveillance data, 2014-2017. International Journal of Infectious Diseases 84S (2019) S10-S14.

22. A. K. Hati, "Studies on dengue and dengue haemorrhagic fever(DHF) in West Bengal State, India,” Journal of Communi-cable Diseases,vol.38,no.2,pp.124-129,2006.

23. Nivedita Gupta, Sakshi Srivastava, Amita Jain, and Umesh C. Chaturvedi. Dengue in India. Indian J Med Res. 2012 Sep; 136(3): 373-390.

24. Anker M, Arima Y. Male-female differences in the number of reported incident dengue fever cases in six Asian countries. Western Pac Surveill Response J 2011;2:17-23.

25. Arima Y, Chiew M, Matsui T, Emerging Disease Surveillance and Response Team, Division of Health Security and Emergencies, World Health Organization Regional Office for the Western Pacific. Epidemiological update on the dengue situation in the Western Pacific Region, 2012. Western Pac Surveill Response J 2015;6:82-9.

26. Nidhi Singla, Preeti Chaudhary, Monika Thakur, Jagdish Chander. Dengue: An Analysis of Epidemiological Pattern Over a Six Year Period. Journal of Clinical and Diagnostic Research. 2016 Dec, Vol-10(12): DC12-DC14.

27. Avinash Kumar, Sharon Rainy Rongpharpi, Shalini Dewan Duggal, Renu Gur, Sanjay Choudhary and Pratima Khare. Clinical, Epidemiological and Microbiological Profile of Dengue Fever at a Tertiary Care Hospital in Delhi, India. J Infect Dis Med 2017, 2:2.

28. Shweta Chitkara, Deepinder Chhina,Veenu Gupta, Rajesh Mahajan, Daaman Sharma. Epidemiology of Dengue Fever among clinically Suspected Febrile Patients at A Tertiary Care Center in Punjab. J Microbiol Infect Dis. 2018; 8 (2):43-48.

29. Sherchand JB, Pandey BD, Haruki K, Jimba M (2001) Serodiagnosis of Japanese encephalitis and dengue virus infection from clinically suspected patients of Nepal. J Inst Med Nepal 23: 26-31.

30. Shah Y, Khadka G,1 Gupta GP,Adhikari N, Poudel A,Pant KP, Dahal B,Pandey BD. (2012) Sero-diagnosis of dengue virus in different hospitals of Nepal. Int $\mathbf{J}$ Infect Microbiol 1: 58-62. 
31. Emran Bin Yunus, Dilrose Banu, Kanak Ranjan Talukder, M Jamal Hossain Chowdhury, A Mannan Bangali and R M Montanar. (2002) Sero-epidemiological study of dengue/dengue haemorrhagic fever in a metropolitan hospital in Bangladesh. Dengue Bull 26: 1-6.

32. Hay SI, Cox J, Rogers DJ, Randolph SE, Stern DI, Shanks GD, Myers MF, Snow RW: Climate change and the resurgence of malaria in the East African highlands. Nature 2002, 415:905-909.

33. Dr. Ganesh Sethi and Aribam Bidyarani Sharma. Climate change and Manipur: Preparations, problems and awareness to face it. International Journal of Applied Research 2017; 3(1): 710-716. 
Figure 1

Dengue positive cases distribution month wise over three year's period

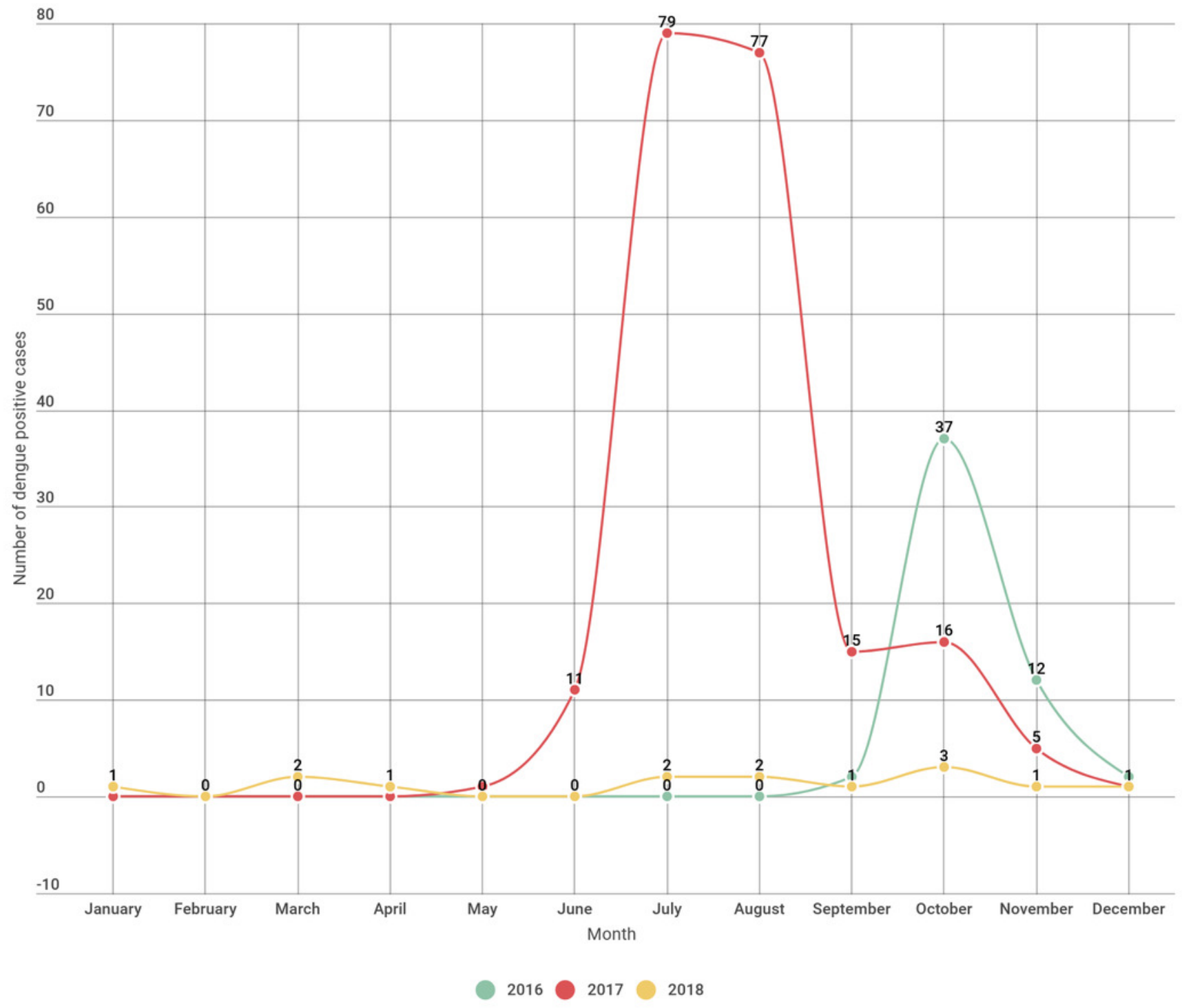


Figure 2

Gender wise dengue positive cases among different age groups

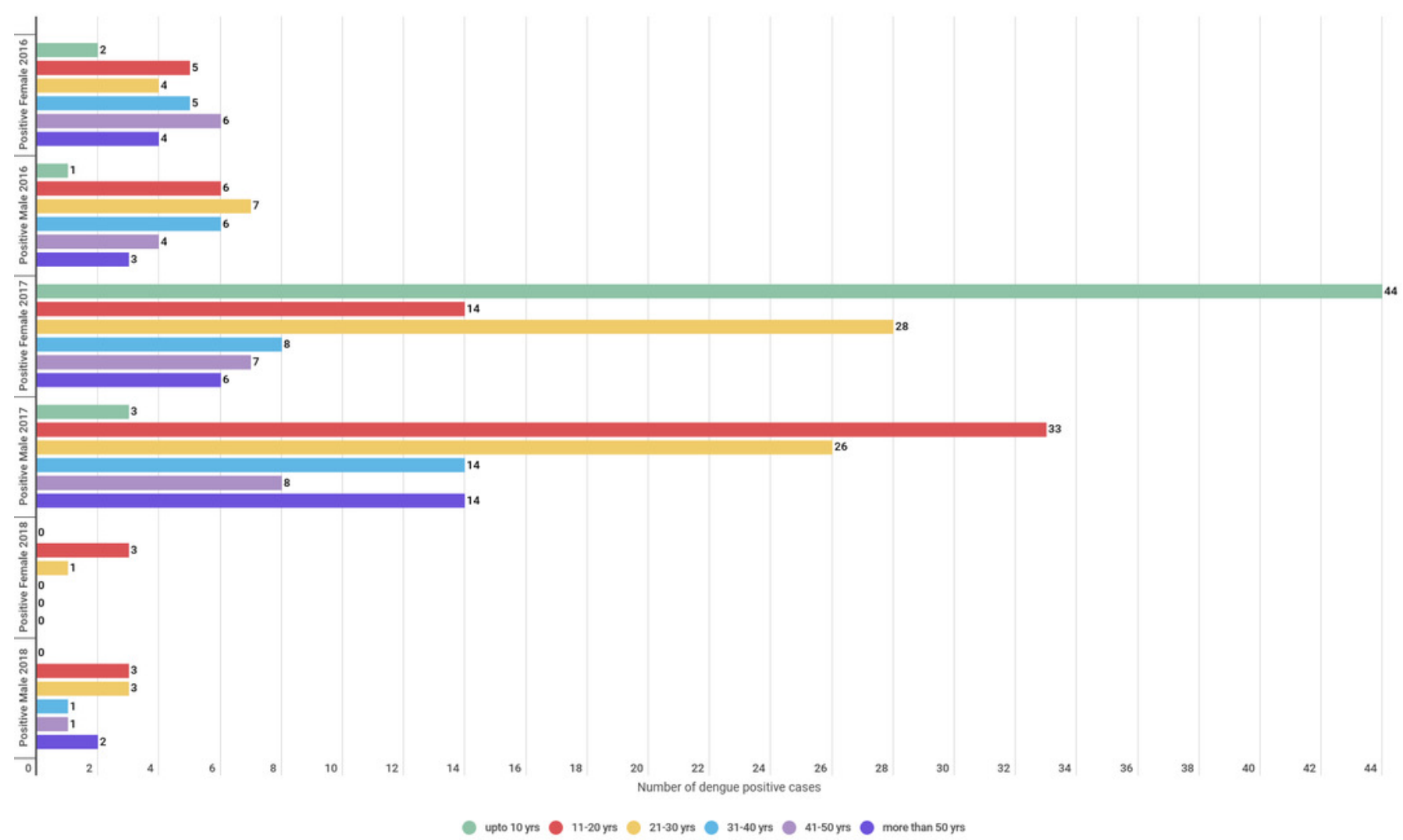


Figure 3

District wise distribution of dengue positive cases in Manipur: 2016-2018

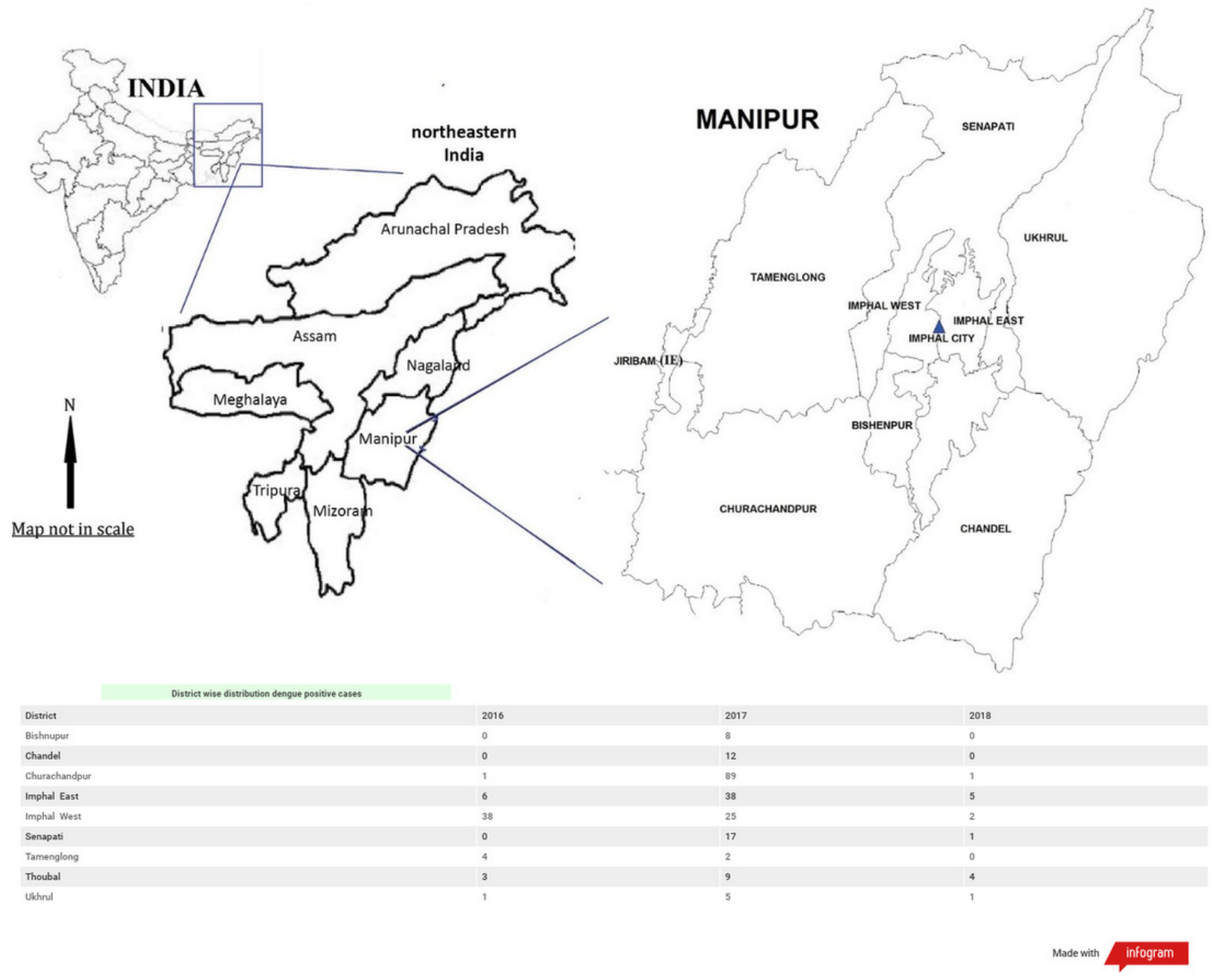


Table $\mathbf{1}$ (on next page)

Year wise distribution of dengue positive cases 


\begin{tabular}{|l|l|l|l|l|}
\hline Year & Total Sample Tested & NSI Positive & IgM Positive & Total \\
\hline 2016 & 251 & $35(13.94 \%)$ & $18(7.17 \%)$ & $53(21.11 \%)$ \\
\hline 2017 & 1286 & $24(1.87 \%)$ & $181(14.07 \%)$ & $205(15.94 \%)$ \\
\hline 2018 & 152 & $4(2.63 \%)$ & $10(6.58 \%)$ & $14(9.21 \%)$ \\
\hline Total & $\mathbf{1 6 8 9}$ & $\mathbf{6 3}(\mathbf{3 . 7 3} \%)$ & $\mathbf{2 0 9}(\mathbf{1 2 . 3 7 \%})$ & $\mathbf{2 7 2}(\mathbf{1 6 . 1 0} \%)$ \\
\hline The chi-square statistic is 94.9796. The $p$-value is $<0.00001$. The result is significant at $p<.05$. \\
\hline
\end{tabular}

1 Table 1. Year wise distribution of dengue positive cases

2 
Table 2 (on next page)

Monthwise/season wise distribution of sero-positive dengue cases 


\begin{tabular}{|c|c|c|c|c|}
\hline $\begin{array}{c}\text { Name of the } \\
\text { Month }\end{array}$ & $\begin{array}{c}\text { Seropositive } \\
\mathbf{( 2 0 1 6 )}\end{array}$ & $\begin{array}{c}\text { Seropositive } \\
\mathbf{( 2 0 1 7 )}\end{array}$ & $\begin{array}{c}\text { Seropositive } \\
\mathbf{( 2 0 1 8 )}\end{array}$ & $\begin{array}{c}\text { Total(Overall } \\
\text { in three years) }\end{array}$ \\
\hline January & 0 & 0 & 1 & 1 \\
\hline February & 0 & 0 & 0 & 0 \\
\hline March & 0 & 0 & 2 & 2 \\
\hline April & 0 & 0 & 0 & 1 \\
\hline May & 0 & 1 & 0 & 11 \\
\hline June & 0 & 11 & 2 & 81 \\
\hline July & 0 & 79 & 2 & 79 \\
\hline August & 0 & 77 & 1 & 18 \\
\hline September & 2 & 15 & 1 & 56 \\
\hline October & 37 & 16 & 1 & 18 \\
\hline November & 12 & 5 & $\mathbf{1 4}$ & 4 \\
\hline December & 2 & 1 & $\mathbf{2 7 2}$ \\
\hline Total & $\mathbf{5 3}$ & $\mathbf{2 0 5}$ & 1 & 1 \\
\hline
\end{tabular}

1 Table 2.Monthwise/season wise distribution of sero-positive dengue cases

2 
Table 3 (on next page)

Gender wise dengue sero-positive distribution 


\begin{tabular}{|c|c|c|c|}
\hline Year & Positive Males & Positive Females & $\begin{array}{c}\text { Total Sero-positive } \\
\text { Sample }\end{array}$ \\
\hline 2016 & 27 & 26 & 53 \\
\hline 2017 & 120 & 85 & 205 \\
\hline 2018 & 10 & 4 & 14 \\
\hline $\begin{array}{l}\text { The chi-square statistic is } 2.1314 \text {. The } p \text {-value is .344481. The result is not } \\
\text { significant at } p<.05 .\end{array}$
\end{tabular}

1 Table 3.Gender wise dengue sero-positive distribution 2 


\section{Table 4(on next page)}

Age wise sero-positive cases 


\begin{tabular}{|l|l|l|l|l|}
\hline Age & $\begin{array}{l}\text { Positive } \\
\mathbf{2 0 1 6}\end{array}$ & $\begin{array}{l}\text { Positive } \\
\mathbf{2 0 1 7}\end{array}$ & $\begin{array}{l}\text { Positive } \\
\mathbf{2 0 1 8}\end{array}$ & Total \\
\hline upto 10 & 3 & 47 & 0 & $50(18.38 \%)$ \\
\hline $11-20$ & 11 & 27 & 6 & $64(23.53 \%)$ \\
\hline $21-30$ & 11 & 54 & 4 & $69(25.37 \%)$ \\
\hline $31-40$ & 11 & 22 & 1 & $34(12.5 \%)$ \\
\hline $41-50$ & 10 & 15 & 1 & $26(9.56 \%)$ \\
\hline more than 50 & 7 & 20 & 2 & $29(10.66 \%)$ \\
& & & & 272 \\
\hline
\end{tabular}

1 Table 4.Age wise sero-positive cases 